\title{
VISIBLE, VERY NEAR IR AND SHORT WAVE IR HYPERSPECTRAL DRONE IMAGING SYSTEM FOR AGRICULTURE AND NATURAL WATER APPLICATIONS
}

\author{
H. Saari ${ }^{\mathrm{a}, *}$, A. Akujärvi ${ }^{\mathrm{a}}$, C. Holmlund ${ }^{\mathrm{a}}$, H. Ojanen ${ }^{\mathrm{a}}$, J. Kaivosoja ${ }^{\mathrm{b}}$, A. Nissinen ${ }^{\mathrm{b}}$, O. Niemeläinen $^{\mathrm{b}}$ \\ ${ }^{a}$ VTT Technical Research Centre of Finland Ltd., FI 02044 Espoo, Finland - (heikki.saari, altti.akujarvi, christer.holmlund, \\ harri.ojanen)@vtt.fi

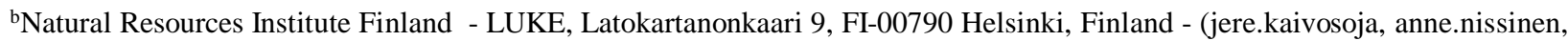 \\ oiva.niemelainen)@luke.fi
}

\section{Commission III, WG III/4}

KEY WORDS: Hyperspectral imaging, microspectrometers, Fabry-Perot, drone, forage quality estimation, water quality monitoring

\begin{abstract}
:
The accurate determination of the quality parameters of crops requires a spectral range from $400 \mathrm{~nm}$ to $2500 \mathrm{~nm}$ (Kawamura et al., 2010, Thenkabail et al., 2002). Presently the hyperspectral imaging systems that cover this wavelength range consist of several separate hyperspectral imagers and the system weight is from 5 to $15 \mathrm{~kg}$. In addition the cost of the Short Wave Infrared (SWIR) cameras is high $(\sim 50 \mathrm{k} €)$. VTT has previously developed compact hyperspectral imagers for drones and Cubesats for Visible and Very near Infrared (VNIR) spectral ranges (Saari et al., 2013, Mannila et al., 2013, Näsilä et al., 2016). Recently VTT has started to develop a hyperspectral imaging system that will enable imaging simultaneously in the Visible, VNIR, and SWIR spectral bands. The system can be operated from a drone, on a camera stand, or attached to a tractor. The targeted main applications of the DroneKnowledge hyperspectral system are grass, peas, and cereals. In this paper the characteristics of the built system are shortly described. The system was used for spectral measurements of wheat, several grass species and pea plants fixed to the camera mount in the test fields in Southern Finland and in the green house. The wheat, grass and pea field measurements were also carried out using the system mounted on the tractor. The work is part of the Finnish nationally funded "DroneKnowledge Towards knowledge based export of small UAS remote sensing technology" project.
\end{abstract}

\section{INTRODUCTION}

The accurate determination of the quality parameters of crops requires a spectral range from $400 \mathrm{~nm}$ to $2500 \mathrm{~nm}$ (Kawamura et al., 2010, Thenkabail et al., 2002). Presently the hyperspectral imaging systems that cover this wavelength range consist of several separate hyperspectral imagers and the system weight is from 5 to $15 \mathrm{~kg}$. In addition the cost of the Short Wave Infrared (SWIR) cameras is high ( $50 \mathrm{k} €)$.

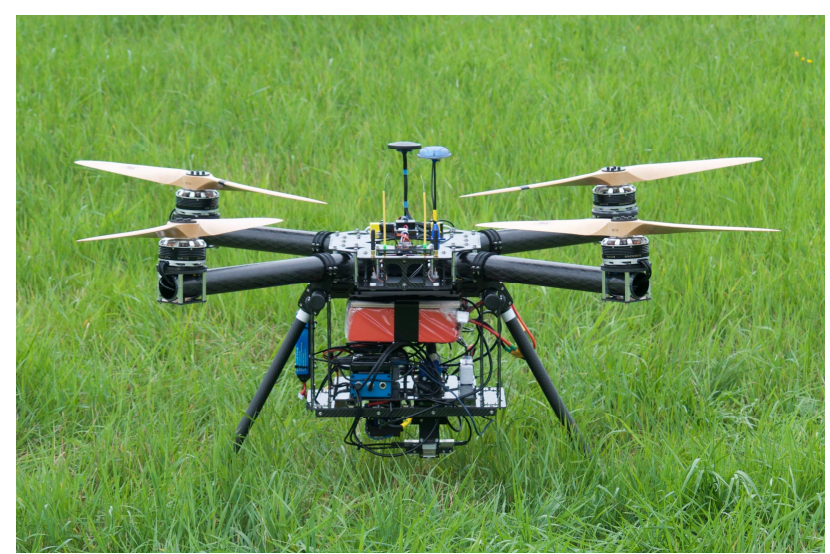

Figure 1 DroneKnowledge hyperspectral imaging system mounted under the Avartek drone.

VTT has previously developed compact hyperspectral imagers for drones and Cubesats for Visible and Very near Infrared
(VNIR) spectral ranges (Saari et al., 2013, Mannila et al., 2013, Näsilä et al., 2016).

Recently VTT has started to develop a drone hyperspectral imaging system that will enable imaging simultaneously in the Visible, VNIR, and SWIR spectral bands.

The work is part of the Finnish nationally funded "DroneKnowledge - Towards knowledge based export of small UAS remote sensing technology" - project. The main applications of the DroneKnowledge hyperspectral system are grass, peas, and cereals.

\section{METHODOLOGY}

The main objectives of the DroneKnowledge drone hyperspectral system development are:

1. The system shall consist of components that allow the total manufacturing cost to be less than $10 \mathrm{k€}$.

2. The total weight of the system should be less than $1 \mathrm{~kg}$.

3. Measurements in the SWIR spectral range can be based on single pixel spectrometers.

Because the project was started only at the beginning of April 2017 the hyperspectral imaging system for the summer 2017 drone campaigns was realized using VTT Piezo-actuated FPI

\footnotetext{
${ }^{*}$ Corresponding author
} 
tunable filter technology (Saari et al. 2013) for Visible-VNIR spectral ranges and on the microspectrometer modules of Spectral Engines Ltd. (Spectral Engines Ltd., 2017) for the SWIR spectral ranges.

The specifications of the built DroneKnowledge hyperspectral imaging system used in summer 2017 are presented in Table 1 .

\begin{tabular}{|c|c|c|}
\hline Parameter & Target value & Remarks \\
\hline $\begin{array}{l}\text { Spectral ranges } \\
\text { Visible } \\
\text { VNIR } \\
\text { SWIR-1 } \\
\text { SWIR-2 } \\
\text { SWIR-3 }\end{array}$ & $\begin{array}{l}400-650 \mathrm{~nm} \\
650-1000 \mathrm{~nm} \\
1350-1650 \mathrm{~nm} \\
1550-1950 \mathrm{~nm} \\
1760-2150 \mathrm{~nm} \\
\end{array}$ & $\begin{array}{l}\text { FPI tunable filter } \\
\text { FPI tunable filter } \\
\text { Spe. Eng. N1.7 } \\
\text { Spe. Eng. N2.0 } \\
\text { Spe. Eng. N2.2 }\end{array}$ \\
\hline $\begin{array}{l}\text { Res. @ FWHM } \\
\text { Visible } \\
\text { VNIR } \\
\text { SWIR-1 } \\
\text { SWIR-2 } \\
\text { SWIR-3 } \\
\end{array}$ & $\begin{array}{l}8-12 \mathrm{~nm} \\
8-16 \mathrm{~nm} \\
12-16 \mathrm{~nm} \\
14-20 \mathrm{~nm} \\
18-24 \mathrm{~nm} \\
\end{array}$ & \\
\hline $\begin{array}{l}\text { Image size/pixels } \\
\text { Visible } \\
\text { VNIR } \\
\text { SWIR-1, - } 2 \&-3 \\
\end{array}$ & $\begin{array}{l}2048 \times 1546 \\
2048 \times 1546 \\
1 \times 1 \\
\end{array}$ & $\begin{array}{l}\text { Visible } \quad \text { and } \\
\text { VNIR image } \\
\text { sensors are Sony } \\
\text { IMX265 }\end{array}$ \\
\hline $\begin{array}{l}\text { Focal length } \\
\text { Visible } \\
\text { VNIR } \\
\text { SWIR-1, -2 \& -3 } \\
\end{array}$ & $\begin{array}{l}12 \pm 0.5 \mathrm{~mm} \\
11 \pm 0.5 \mathrm{~mm} \\
10 \pm 0.5 \mathrm{~mm} \\
\end{array}$ & $\begin{array}{l}\text { The exact value } \\
\text { is known after } \\
\text { geometrical } \\
\text { calibration }\end{array}$ \\
\hline $\begin{array}{l}\text { GSD/cm@120 m } \\
\text { Visible } \\
\text { VNIR } \\
\text { SWIR-1, -2 \& -3 }\end{array}$ & $\begin{array}{l}3.5 \mathrm{~cm} \\
3.8 \mathrm{~cm} \\
600 \mathrm{~cm}\end{array}$ & \\
\hline $\begin{array}{l}\text { Frame rate } \\
\text { Visible } \\
\text { VNIR } \\
\text { SWIR-1, }-2 \&-3 \\
\end{array}$ & $\begin{array}{l}20 \text { frames/s } \\
20 \text { frames/s }\end{array}$ & \\
\hline Dimensions & $\begin{array}{l}<200 \mathrm{~mm} \times 200 \\
\mathrm{~mm} \times 150 \mathrm{~mm}\end{array}$ & $\begin{array}{l}\text { The system is } \\
\text { large because } \\
\text { there was no time } \\
\text { to optimize the } \\
\text { system. }\end{array}$ \\
\hline Mass & $<3 \mathrm{~kg}$ & \\
\hline $\begin{array}{l}\text { Power } \\
\text { consumption }\end{array}$ & $\sim 15 \mathrm{~W}$ & \\
\hline
\end{tabular}

Table 1. Preliminary specifications of the DroneKnowledge Summer 2017 hyperspectral imaging system.

\section{RESULTS AND VALIDATION}

\subsection{Design overview}

The design of the DroneKnowledge hyperspectral imaging system was completed in Mid-May 2017. The 3D view of the system mounted to the drone support is shown in Figure 2.

The DroneKnowledge hyperspectral imaging system was calibrated in May 2017.

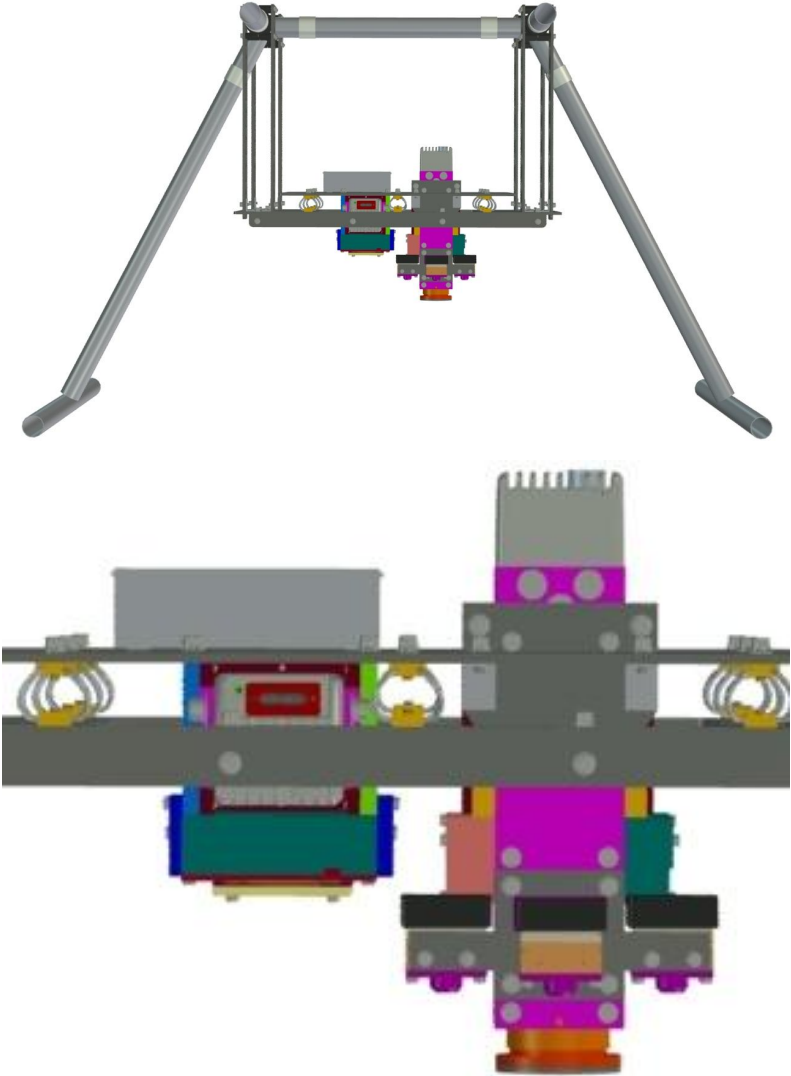

Figure 2 DroneKnowledge hyperspectral imaging system mounted to the drone.

\subsection{Aphid infected Pea studies}

Pea plants can suffer from pea aphid (Acyrthosiphon pisum) infections (see Figure 3 ) and in many cases this infection is so severe that pesticide application is needed on the pea fields. The objective of DroneKnowledge project is to find out if the spectral reflectance of aphid infected pea plants is different from the reflectance of healthy plants. Two pea cultivars were selected for the green house studies: Polymephus (Monsanto), early flowering, and Donana (Nunhems), late flowering. The aphid population grows very rapidly: the population can grow from one female per plant to 100 aphids per plant in 11 days (see Figure 4).

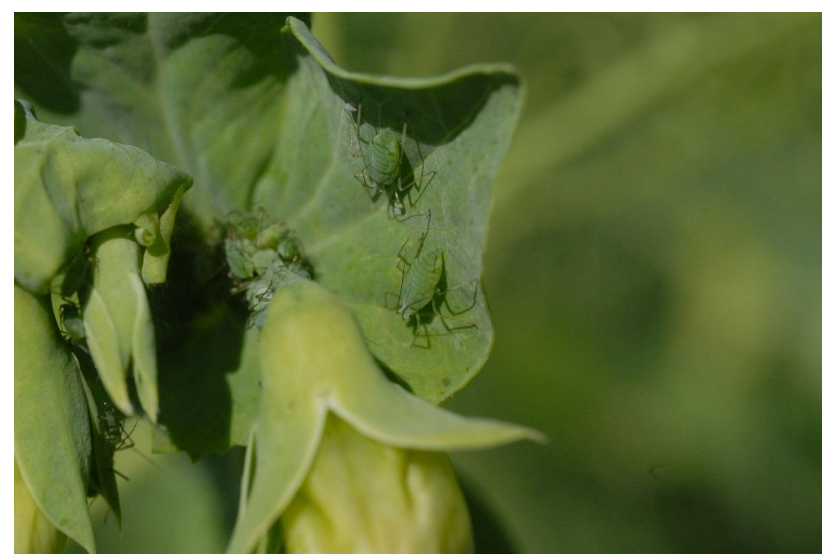

Figure 3 Aphids on the pea stipule photographed by Anne Nissinen, Natural Resources Institute Finland -Luke. 


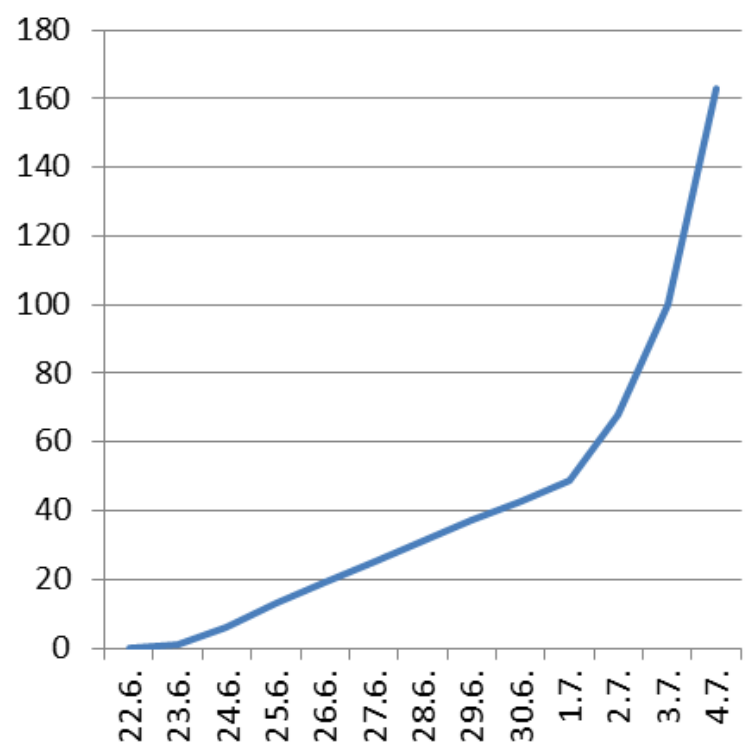

Figure 4 Estimation of pea aphid population growth according to preliminary test.

The pea aphid infection study was carried out in the green house of Natural Resources Institute Finland in Jokioinen, Finland. In total 8 pea plants of both species were infected with aphids and 8 uninfected plants were also grown in the same greenhouse conditions as the infected plants. The goal was to find out at which stage of the aphid population growth the infection can be detected based on spectral reflectance change.

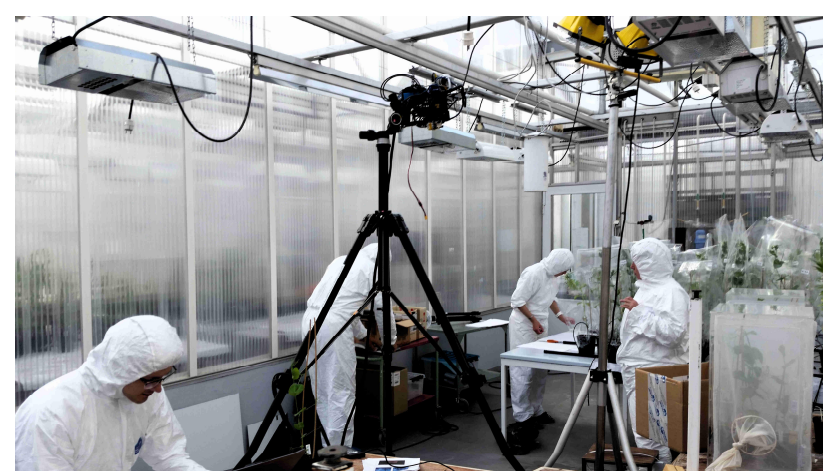

Figure 5 DroneKnowledge VIS-VNIR-SWIR hyperspectral imaging system on a camera mount used for spectral

reflectance measurements of pea plants in the green house.

The configuration used for the spectral reflectance measurements of aphid infected and uninfected control pea plants is shown in Figure 5. Halogen lamps were used for the illumination of plants. The measurements were performed on 17.7, 24.7 and 31.7.2017. After each measurement session, the pea plants were cut and aphids removed by rinsing the plant debris on sieve series. The aphids gathered into the sieves were stored in $70 \%$ ethanol for counting the number of aphids per plant later.

The hyperspectral imaging of aphid infected pea plants were also carried on a pea (cv, Jymy) field of Natural Resources Institute Finland in Jokioinen, Finland (see Figure 6). The measurements were carried out with the imaging system mounted on the tractor (see Figure 7). At 19 sampling points separated by $11.5 \mathrm{~m}, 10$ plants were checked for presence/absence of aphids. Based on this inspection, $76 \%$ of the plants were found to be infected by aphids. In addition one pea plant was cut in each point and the aphids stored in $70 \%$ ethanol for a more precise population estimate. The hyperspectral measurements were made by stopping the tractor at each of the 19 aphid sampling locations. Between the sampling points the tractor was moving at a slow speed and the measurement data was recorded continuously.

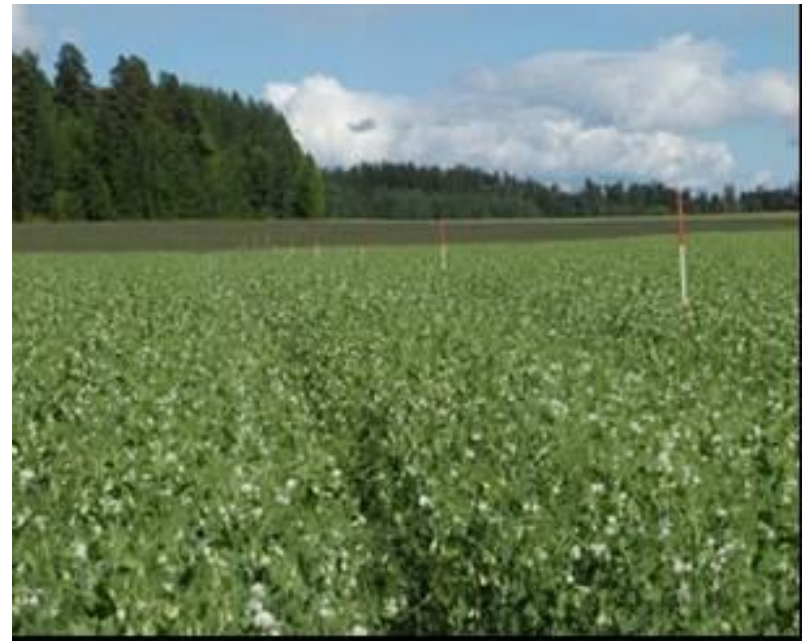

Figure 6 Aphid infected pea field. Photo: Anne Nissinen

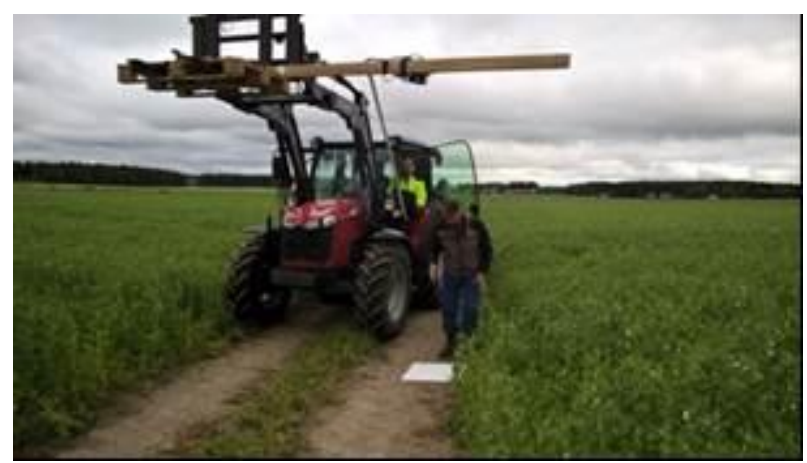

Figure 7 DroneKnowledge VIS-VNIR-SWIR hyperspectra imaging system mounted on the tractor at pea field in

Jokioinen, Finland on 26.7.2017. Photo: Oiva Niemeläinen

\subsection{Grass quality and quantity studies}

In Nordic countries cow nutrition is based very strongly on grass silage made of mixed sward of timothy and meadow fescue, and of cereals (barley, oats) as dried grains or as whole crop silage. The feeding quality of grass silage is described with the so-called D-value, which describes the content of digestible organic matter in the Dry Matter (DM). D-value decreases progressively as the forage matures and stem/leaf ratio increases. D-value is a good indication of overall nutritive value. In Nordic countries the grass sward is cut normally three times for silage during the growing season. The main yield comes from the first cut which is made in between second and fourth weeks of June in Southern Finland pending on the accumulation of growing degree days (GDD), i.e., on weather conditions in May and June. In Spring growth the DM yield increases but and at the same time the D-value decreases as a function of the GDDs. For the optimization of the D-value the standard procedure is to send grass samples for a laboratory 
determination of the D-value. In laboratory the D-value is determined from dried, ground grass samples based on spectral reflectance measurements in the wavelength range $1200-2500$ $\mathrm{nm}$ (Nousiainen et.al., 2004).

In our study the grass forage field tests were made at the test sites of Natural Resources Institute Finland (LUKE) in Maaninka and Jokioinen, Finland. The new VIS-VNIR-SWIR hyperspectral imaging system was used in LUKE Jokioinen site on 24.7, 26.7, 1.8 and 14.8.2017 and at the Boreal Plant Breeding Ltd. test field in Jokioinen on 24.7.2017 for measuring the harvest growing for the second cut in the season.

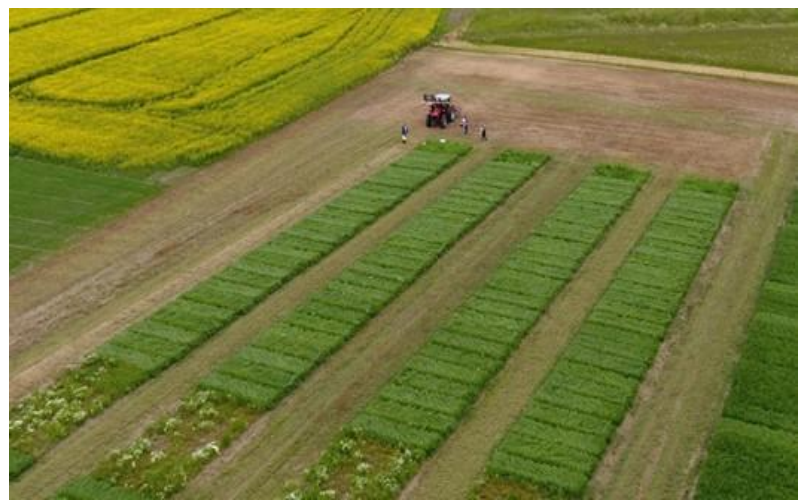

Figure 8 Photograph of the Boreal Plant Breeding Ltd. grass variety testing field in Jokioinen on 24.7.2017.

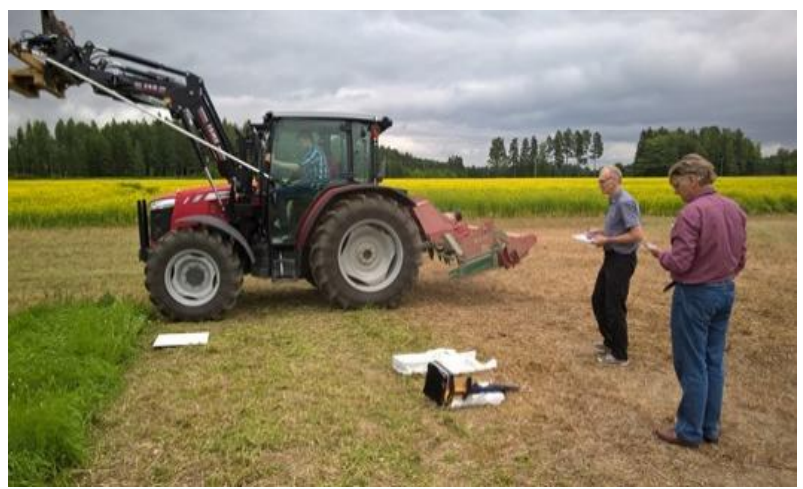

Figure 9 DroneKnowledge VIS-VNIR-SWIR hyperspectral imaging system mounted on the tractor at grass field in Jokioinen, Finland on 24.7.2017.

The test fields in Luke Jokioinen site contained test plots with different nitrogen fertilizing amounts $0,50,75,100,125$ and $150 \mathrm{~kg} / \mathrm{ha}$. The grass on the test plots consisted of timothy and meadow fescue. Because of the big variations in the fertilizer amounts of test plots and different harvest dates it was expected that there would be large differences in the grass sward and in the quality and quantity of the harvested yield. The first harvest was cut on 6.6, 15.6, 19.6, 28.6 and 7.7.2017 at the Luke, Ilmala test field in Jokioinen.

Another field was used for the studies of the second cut. In that field the first cut was harvested on 19th of June, and the experimental plots were fertilized on 22nd of June with nitrogen rates $0,25,50,75,100,125$ and $150 \mathrm{~kg} / \mathrm{ha}$. At the rate $100 \mathrm{~kg} \mathrm{~N} / \mathrm{ha}$ three different nitrogen fertilizer formulas were used - ammonium sulphate, liquid organic nitrogen fertilizer, and ammonium nitrate, which was used also in applying all the other nitrogen rates. Second cut test harvest were taken on 25.7., 1.8. and 15.8. Size of the fertilizer application main plot was $3 \mathrm{~m} \mathrm{x} 12 \mathrm{~m}$, and size of the harvest time sub-plot was $1,5 \mathrm{~m} \mathrm{x} 3 \mathrm{~m}$.

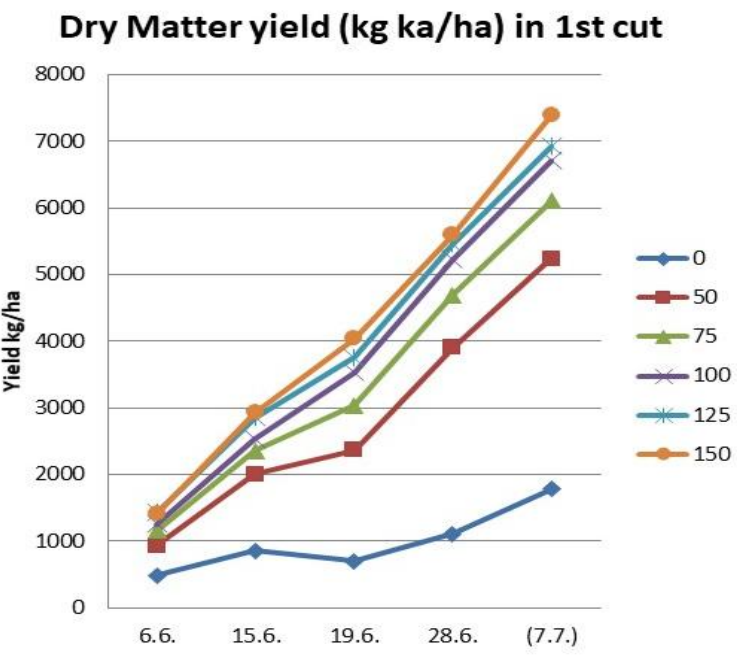

Figure 10 Dry matter yield of the grass sward in first cut as function of harvest time and nitrogen application rates $(\mathrm{kg} / \mathrm{ha})$ at the Luke test plots in Jokioinen, Finland.

\subsection{Preliminary analysis results of green house pea plant measurements}

The examples of the infected and non-infected pea plant leaf reflectance spectra measured on 24.7.2017 are shown in Figures 11 and 12. The preliminary results indicate that there are differences on average spectral reflectances in the wavelength range $400-975 \mathrm{~nm}$ for the infected and noninfected pea plants but because the analysis of the pea plant measurement data has just started it is too early to draw any conclusions.

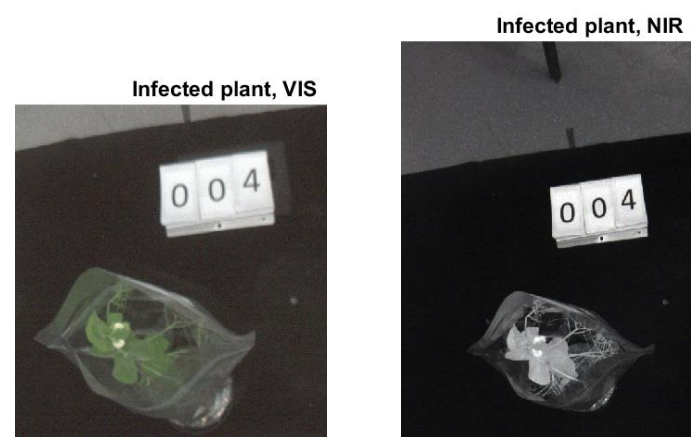

Figure 11 Images of an infected pea plant recorded with the DroneKnowledge VIS and VNIR Hyperspectral cameras in the green house on 24.7.2017.

\subsection{Preliminary results analysis of grass field tests}

The measurement result from the LUKE grass test plots in Jokioinen recorded on 1.8.2017 are shown in Figures 13 and 14.

\section{FIRST TRIALS WITH THE DRONE}

The first test flight with DroneKnowledge VIS-VNIR-SWIR HIS system was carried on 29.8.2017 in Luoma, Kirkkonummi, Finland. 


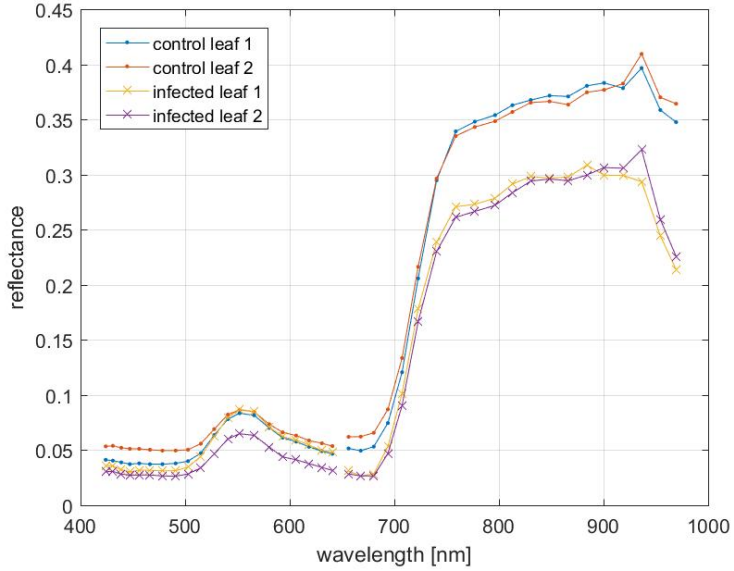

Figure 12 Measured spectral reflectances of two leaves of uninfected control pea plant and two leaves of an infected pea plant.
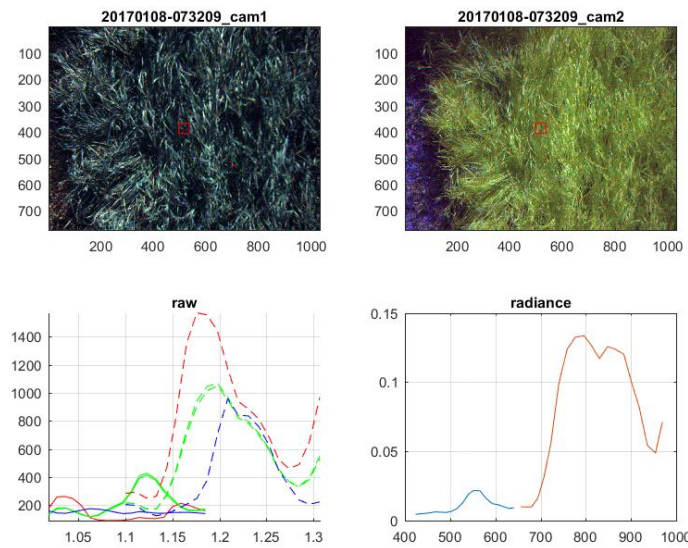

Figure 13 False color images of the DroneKnowledge VIS (cam1) and VNIR (cam2) hyperspectral cameras, raw signal and radiance signal at the selected subwindow.
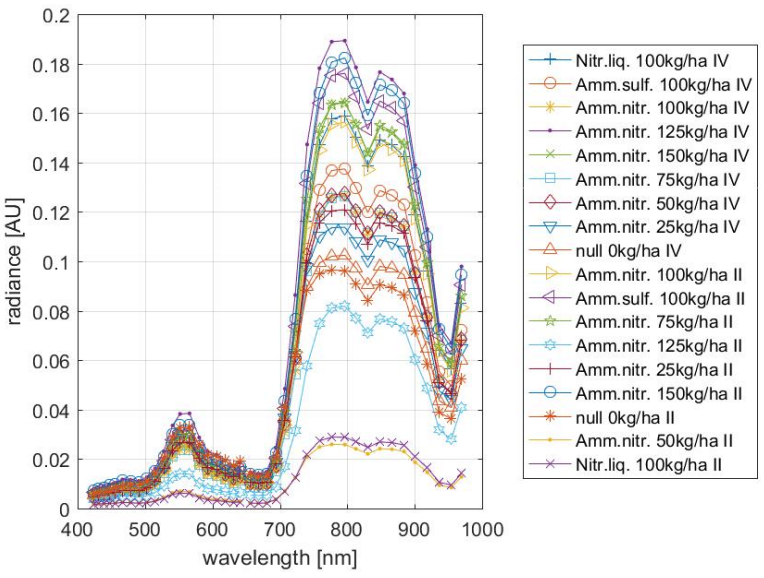

Figure 14 Measured spectral radiances of grass test plots with different Nitrogen fertilizer amounts measured on 1.8.2017 at the Luke. Jokionen grass test field with VIS and NIR hyperspectral cameras.

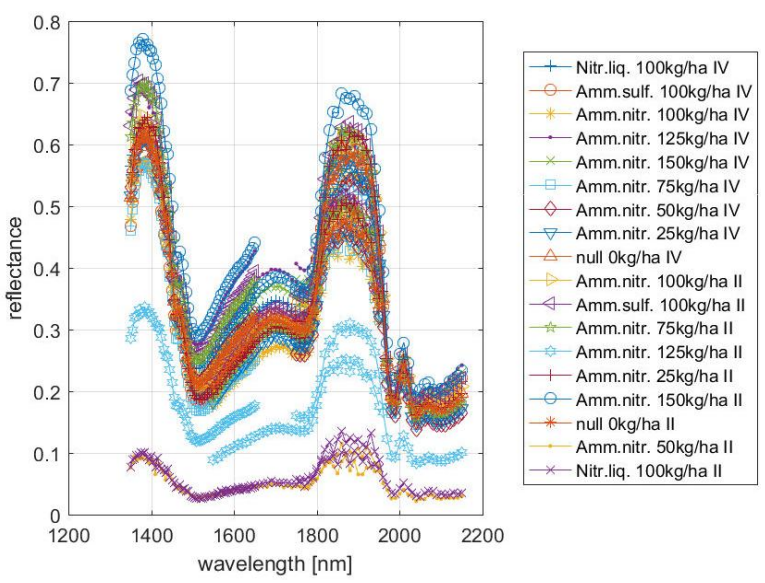

Figure 15 Measured spectral reflectances of grass test plots with different Nitrogen fertilizer amounts measured on

1.8.2017 at the Luke Jokionen grass test field with Spectral Engines microspectroemeter modules SE-N1.7, SE-N2.0 and SE-N2.2.

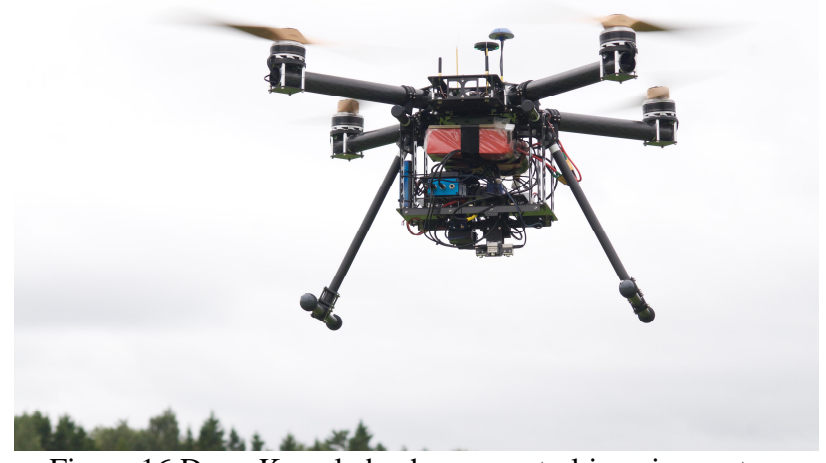

Figure 16 DroneKnowledge hyperspectral imaging system airborne with the Avartek drone.

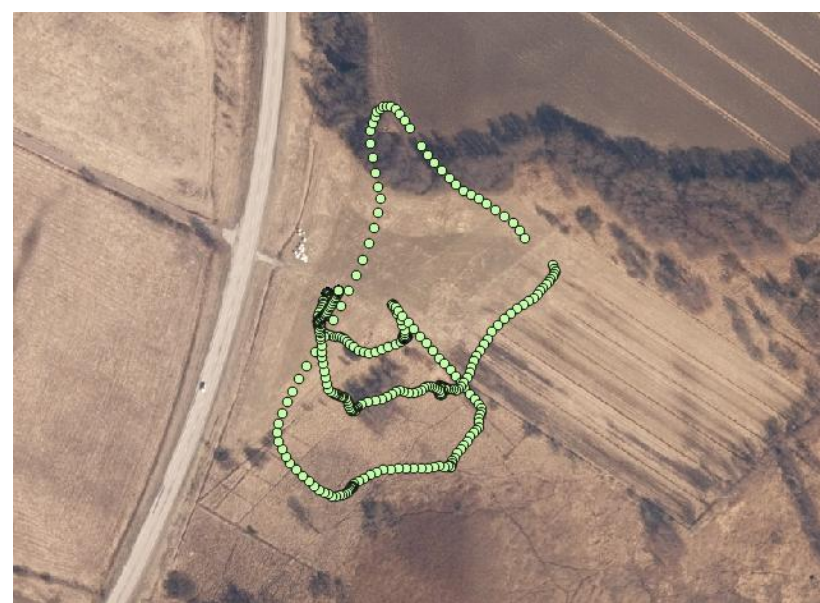

Figure 17 During the first test flight the drone was flown manually over various types of vegetation. Base ortho photo courtesy of National Land Survey of Finland.

Altitude $90 \mathrm{~m}$ above field, typical ground speed varied from 4 $\mathrm{m} / \mathrm{s}$ to $8 \mathrm{~m} / \mathrm{s}$. Weather conditions were cloudy and windy, meaning less than optimal conditions for spectral imaging. 


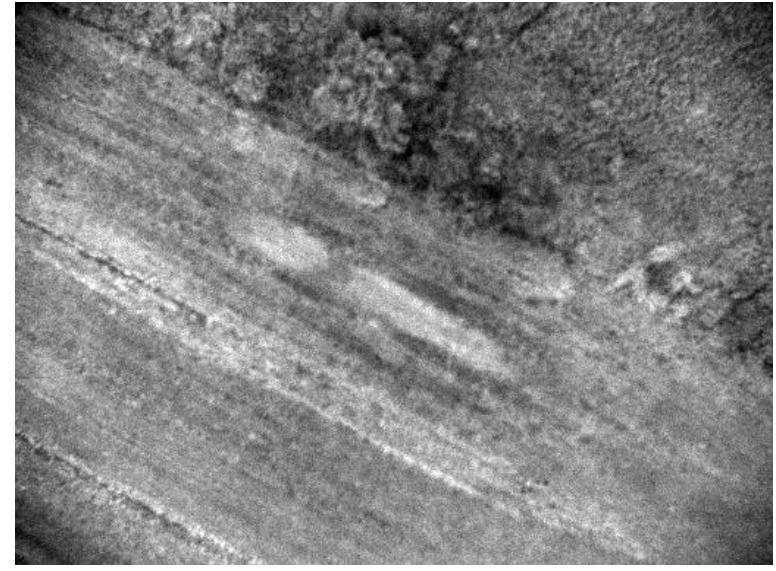

Figure 18 VIS camera view at $552 \mathrm{~nm}$.

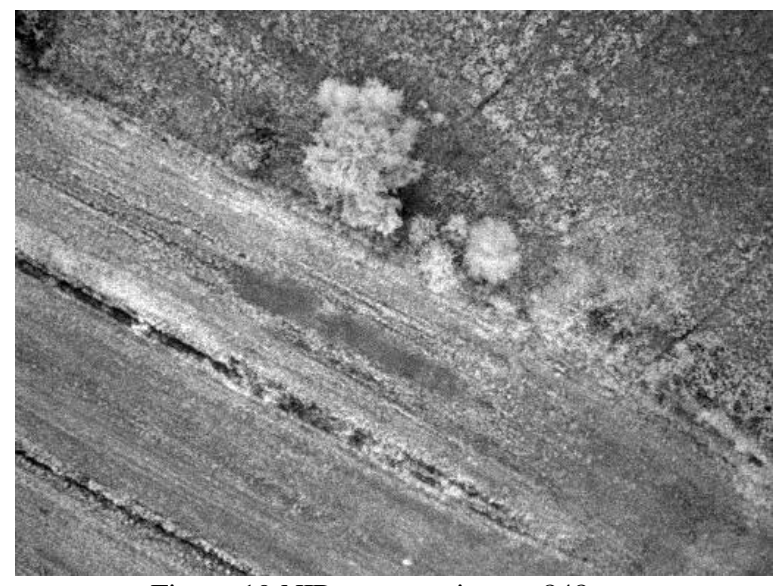

Figure 19 NIR camera view at $848 \mathrm{~nm}$.

\section{CONCLUSIONS}

We have described the design of a new type of hyperspectral imaging system that can cover the wavelength range $400-2500$ $\mathrm{nm}$ with technologies that enable to build a low weight (target weight $<1 \mathrm{~kg}$ ), cost effective (product price range $\sim 10 \mathrm{k€}$ ) system. Because the development for the summer 2017 field tests was started only in April 2017 the first system was integrated using conventional Piezo-actuated FPI tunable filter and RGB image sensor based technology (Saari et al., 2013, Mannila et al., 2013, Näsilä et al., 2016) for the Visible (400 $650 \mathrm{~nm})$ and VNIR (650 - $975 \mathrm{~nm}$ ) hyperspectral imagers. The SWIR spectral range in summer 2017 system was built based on Spectral Engines SE-N1.7, SE-N2.0 and SE-N2.2 which could cover the spectral range $1350-2150 \mathrm{~nm}$.

In summer 2017 we carried out an extensive test program with our hyperspectral imaging system fixed to the camera mount, to the tractor attachment and to the drone. We have shown preliminary results of aphid infected pea plants measured using the camera mount and halogen lamp illumination. We used the system fixed to the tractor attachment for the measurements of the grass test fields of Boreal Plant Breeding Ltd. and of Natural Resources Institute Finland (LUKE) in Jokioinen, Finland. Finally we could also demonstrate that our system can be used with a drone by carrying out a test flight on 29.8.2017.

We have performed only very preliminary analysis of the acquired measurement data on aphid infected pea plants and grass test plots. This is why it is too early to draw any conclusions on the capability of the proposed measurement system to provide the needed information of the aphid infection status of pea plants or of the grass silage quality and quantity. Our results are promising and our approach seems to have the capability to achieve the required performance. However, based on the analysis of the acquired test data we have already noticed several items that must be improved in our hyperspectral system for the summer 2018 test campaigns. One lesson learned was that we must include in our system up and down looking irradiance monitoring sensors for the whole wavelength range in the future system. The SWIR spectral range must also be improved to cover the whole range 1000 $2500 \mathrm{~nm}$.

\section{ACKNOWLEDGEMENTS}

This research has been co-financed by the Finnish Funding Agency for Innovation Tekes (grant 6944/31/2016).

Drone prototype and drone operation by Avartek (www.avartek.fi).

\section{REFERENCES}

Kawamura, K., Watanabe, N., Sakanoue S., Lee, H.J., Inoue Y and Odagawa, S., 2010. Testing genetic algorithm as a tool to select relevant wavebands from field hyperspectral data for the estimating pasture mass and quality in a mixed sown pasture using partial squares regression. Grassl. Sci 56:205-216.

Thenkabail, P., Smith, R., and Depauw, E., 2002. Evaluation of narrowband and broadband vegetation indices for determining optimal hyperspectral wavebands for agricultural crop characterisation. Photogrammetric Engineering and Remote Sensing 68, pp. 607 - 621.

Saari, H., Pölönen, I., Salo, H., Honkavaara, E., Hakala, T., Holmlund, C., Mäkynen, J., Mannila, R., Antila, T. and Akujärvi, A., 2013. Miniaturized hyperspectral imager calibration and UAV flight campaigns. Proc. SPIE 8889.

Mannila, R., Näsilä A., Viherkanto, K., Holmlund, C. and Näkki I., 2013. Spectral imager based on Fabry-Perot interferometer for Aalto-1. Proc. SPIE 8870.

Näsilä A., Holmlund, C., Mannila, R., Näkki, I., Ojanen, H., Saari, H., Fussen, D., Pieroux, D. and Demoulin, P., 2016. PICASSO VISION instrument design, EM test results and FM development status. Proc. SPIE 10001.

Spectral Engines Ltd. 2017. https://www.spectralengines.com/ images/files/spectral_engines_nseries_2017_product_brochure. pdf, downloaded 18.5.2017.

Nousiainen, J., S. Ahvenjärvi, M. Rinne, M. Hellämäki, and P. Huhtanen. 2004. Prediction of indigestible cell wall fractions of grass silage by near infrared reflectance spectroscopy. Anim. Feed Sci. Technol. 115:295-311.

National Land Survey of Finland, file service of open data, colour orthophoto, CC BY 4.0 license, retrieved 30.8.2017. 